\title{
PENGARUH WEB E-COMMERCE, KUALITAS PRODUK DAN KUALITAS LAYANAN TERHADAP KEPUASAN KONSUMEN
}

\author{
Fibria Anggraini Puji Lestari \\ Program Studi Informatika, FTIK, Universitas Indraprasta PGRI \\ Jl. Raya Tengah, Kelurahan Gedong, Pasar Rebo, Jakarta Timur \\ email: fap102@yahoo.com
}

Diterima: Februari 2018; Disetujui: Maret 2018; dipublikasikan: April 2018

\begin{abstract}
ABSTRAK
Penelitian ini menganalisis pengaruh website e-commerce,kualitas produk dan kualitas layanan terhadap kepuasan konsumen. Pada setiap badan usaha yang bergerak dibidang jasa terutama $e$ commerce online sangatlah penting untuk memperhatikan kualitas produk dan pelayanannya,karena berhubungan langsung dengan kepuasan yang dirasakan oleh pelanggan yang kemudian timbul loyalitas dari konsumen yang menggunakan jasa tersebut. Pengaruh kualitas produk dan layanan kepada pelanggan dikatakan sangat penting karena baik buruknya kualitas produk dan layanan yang ditawarkan akan berpengaruh terhadap kepercayaan dan kesetiaan pelanggan (loyalitas pelanggan).Hai ini dapat dilihat dari hasil penelitian yang menunjukkan adanya pengaruh web e-commerce ,kualitas produk dan layanan terhadap kepuasan konsumen.
\end{abstract}

Kata kunci: E-Commerce, Kualitas Produk, Kualitas layanan, Kepuasan konsumen

\begin{abstract}
This research analyzes the influence of e-commerce website, product quality and service quality to customer satisfaction. In every business entity engaged in services, especially e-commerce online is very important to pay attention to the quality of products and services, because it is directly related to the satisfaction felt by the customer who then arise the loyalty of consumers who use these services. The influence of product and service quality to the customer is said to be very important because the good quality of the products and services offered will affect the trust and the customer's loyalty. This can be seen from the result of research showing the influence of e-commerce web, product quality and service to customer satisfaction.
\end{abstract}

Keywords: E-Commerce, Product Quality, Service Quality, Consumer Satisfaction 


\section{PENDAHULUAN}

Perkembangan internet menyebabkan terbentuknya sebuah dunia baru yang lazim disebut dunia maya. Di dunia maya ini setiap individu memiliki hak dan kemampuan untuk berinteraksi dengan individu lain tanpa batasan apa pun yang dapat menghalanginya. E-commerce adalah suatu jenis dari mekanisme bisnis secara elektronik yang memfokuskan diri pada transaksi bisnis berbasis individu dengan menggunakan internet (teknologi berbasis jaringan digital) sebagai medium pertukaran barang atau jasa baik antara dua buah institusi (busines stobusiness) dan konsumen langsung (busines sto consumer), melewati kendala ruang dan waktu yang selama ini merupakan hal-hal yang dominan..Dengan aplikasi e-commerce, seyogyanya hubungan antar perusahaan dengan entitas eksternal lainnya (pemasok, distributor, rekanan, konsumen) dapat dilakukan secara lebih cepat, lebih intensif, dan lebih murah daripada aplikasi prinsip manajemen secara konvensional (door to door, one-to-one relationship). Maka e-commerce bukanlah sekedar suatu mekanisme penjualan barang atau jasa melalui medium internet, tetapi juga terhadap terjadinya sebuah transformasi bisnis yang mengubah cara pandang perusahaan dalam melakukan aktivitas usahanya. Membangun dan mengimplementasikan sebuah system. E-commerce bukanlah merupakan proses instant, namun merupakan transformasi strategi dan system bisnis yang terus berkembang sejalan dengan perkembangan perusahaan dan teknologi.

Indonesia merupakan negara dengan pertumbuhan e-Commerce tertinggi di dunia. Beberapa tahun terakhir, makin banyak pelaku usaha, baik perusahaan besar maupun ritel, beralih atau mengembangkan usaha ke arah digital.Jumlah pelaku e-Commerce akan terus bertumbuh, hal ini diperkuat dengan sejumlah survei lembaga riset teknologi informasi komunikasi dalam dan luar negeri. "Data Sensus Ekonomi 2016 dari Badan Pusat Statistik (BPS) menyebutkan, industri e-Commerce Indonesia dalam sepuluh tahun terakhir tumbuh sekitar tujuh belas persen dengan total jumlah usaha $\underline{e}$-Commerce mencapai 26,2 juta unit.

Berdasarkan latar belakang diatas peneliti tertarik untuk mengambil judul "Analisis Pengaruh Website E-Commerce dan Kualitas Produk terhadap Kepuasan Konsumen.

E-Commerce menurut Ramanathan et al., 2012 merupakan penggunaan teknologi elektronik untuk melakukan penjualan, periklanan dengan menggunakan internet berdasarkan konteks B2B ( Business to Business) dan B2C (Business to Costumer) serta untuk meningkatkan fungsi internal (seperti pemrosesan/ penetapan order), dan untuk menfasilitasi konumikasi dengan mitra supply chain. E-commerce akan merubah semua kegiatan marketing dan juga sekaligus memangkas biaya-biaya operasional untuk kegiatan trading (perdagangan).

Proses yang ada dalam E-commerce adalah sebagai berikut: (a) Presentasi electronis (Pembuatan Web site) untuk produk dan layanan, (b) Pemesanan secara langsung dan tersedianya tagihan, (c) Otomasi account Pelanggan secara aman (baik nomor rekening maupun nomor Kartu Kredit), (d) Pembayaran yang dilakukan secara Langsung (online) dan penanganan transaksi.

E-Commerce dapat dibagi menjadi beberapa jenis yang memiliki karakteristik berbeda-beda diantaranya:

1. Business to Business (B2B)

Business to Businesse Commerce memiliki karakteristik; (a) Tradingpartners yang sudah diketahui dan umumnya memiliki hubungan (relationship) yang cukup lama. (b) Informasi hanya dipertukarkan dengan partner tersebut. Dikarenakan sudah mengenal lawan komunikasi, maka jenis informasi yang dikirimkan dapat disusun sesuai dengan kebutuhan dan kepercayaan (trust), (c) Pertukaran data (data exchange) berlangsung berulang-ulang dan secara berkala, misalnya setiap hari, dengan format data yang sudah disepakati bersama.

Dengan kata lain, servis yang digunakan sudah tertentu. Hal ini memudahkan pertukaran data untuk dua entiti yang menggunakan standar yang sama, yaitu: (1) Salah satu pelaku dapat melakukan inisiatif untuk mengirimkan data, tidak harus menunggu parternya, (2) Model yang umum digunakan adalah peer-to-peer, dimana processing intelligence dapat di distribusikan di kedua pelaku bisnis. Business to Business Commerce umumnya 
menggunakan mechanisme Electronic Data Interchange (EDI).

2. Business to Constumer (B2C)

Business to Constumere Commerce memiliki karakteristik sebagai berikut : (a) Terbuka untuk umum,dimana informasi disebarkan keumum, (b) Servis yang diberikan bersifat umum (generic) dengan mekanisme yang dapat digunakan oleh khalayak ramai. Sebagai contoh, karena sistem Web sudah umum digunakan maka servis diberikan dengan menggunakan basis Web, (c) Servis diberikan berdasarkan permohonan (ondemand). Konsumer melakukan inisiatif dan produser harus siap memberikan respon sesuai dengan permohonan, (d) Pendekatan client/server sering digunakan dimana diambil asumsi client (consumer) menggunakan sistem yang minimal (berbasis Web) dan processing (business procedure) diletakkan disisi server.

3. Perdagangan Kolabratif.(collaborative commerce).

Dalam e-commerce, para mitra bisnis berkolaborasi (alih-alih membeli atau menjual) secara elektronik. Kolaborasi semacam ini seringkali terjadi antara dan dalam mitra bisnis di sepanjang rantai pasokan.

4. Consumen to consumen $(\mathrm{C} 2 \mathrm{C})$

Dalam C2C seseorang menjual produk atau jasa ke orang lain. Dapat juga disebut sebagai pelanggan ke palanggan yaitu orang yang menjual produk dan jasa ke satu sama lain.

5. Comsumen to Business(C2B).

Dalam C2B konsumen memeritahukan kebutuhan atas suatu produk atau jasa tertentu, dan para pemasok bersaing untuk menyediakan produk atau jasa tersebut ke konsumen. Contohnya di priceline.com, dimana pelanggan menyebutkan produk dan harga yang diinginkan, dan priceline mencoba menemukan pemasok yang memenuhi kebutuhan tersebut. 6. Perdagangan Intrabisnis (Intra organisasional)

Dalam situasi ini perusahaan menggunakan ecommerce secara internal untuk memperbaiki operasinya. Kondisi khusus dalam hal ini disebut sebagai e-commerce B2E (business to its employees) yang digambarkan dalam studi kasus terbuka.

7. Pemerintah keWarga (Goverment to Citizen-G2C)

Dalam kondisi ini sebuah entitas (unit) pemerintah menyediakan layanan ke para warganya melalui teknologi E-commerce. Unit-unit pemerintah dapat melakukan bisnis dengan berbagai unit pemerintah lainnya serta dengan berbagai perusahaan (G2B). Egoverment yaitu penggunaan teknologi internet secara umum dan e-commerce secara khusus untuk mengirimkan informasi dan layanan publik ke warga, mitra bisnis, dan pemasok entitas pemerintah, serta mereka yang bekerja di sektor publik.

8. Perdagangan Mobile (mobile commerce-m-commerce).

Ketika e-commerce dilakukan dalam lingkungan nirkabel, seperti dengan menggunakan telepon selluler untuk mengakses internet dan berbelanja, maka hal ini disebut $m$-commerce.

Kualitas produk menurut Vincent Gaspersz (2005 dalam Alma, 2011) dimensi-dimensi kualitas produk terdiri dari: (a) Kinerja (performance), yaitu karakteristik operasi pokok dari produk inti, (b) Ciri-ciri atau keistimewaan tambahan (features), yaitu karakteristik sekunder atau pelengkap, (c) Kehandalan (reliability), yaitu kemungkinan kecil akan mengalami kerusakan atau gagal pakai, (d) Kesesuaian dengan spesifikasi (conformance to specification), yaitu sejauh mana karakteristik desain dan operasi memenuhi standar-standar yang telah ditetapkan sebelumnya, (e) Daya tahan (durability), yaitu berkaitan dengan berapa lama produk tersebut dapat terus digunakan, (f) Serviceability, meliputi kecepatan, kompetensi, kenyamanan, mudah direparasi, penanganan keluhan yang memuaskan, (g) Estetika, yaitu daya tarik produk terhadap panca indera.

Kualitas layanan yang meliputi lima dimensi (Zeithami, 2014), yaitu: (1) Tangibles (bukti langsung), yaitu kemampuan suatu perusahaan dalam menunjukan eksistensinya kepada pihak eksternal. Penampilan dan kemampuan sarana dan prasarana fisik perusahaan dan keadaan lingkungan sekitarnya adalah bukti nyata dari pelayanan yang diberikan perusahaan, (2) Reliability (kehandalan), yaitu kemampuan untuk memberikan pelayanan yang dijanjikan 


\section{Sosio e-kons}

Volume 10, No. 1, 2018, pp. 87-95

e-ISSN: 2502-5449

p-ISSN: 2085-2266

http://journal.lppmunindra.ac.id/index.php/sosio_ekons

dengan segera, akurat dan memuaskan. Kinerja harus sesuai dengan harapan pelanggan yang berarti ketepatan waktu, pelayanan yang sama untuk semua pelanggan tanpa kesalahan, sikap simpatik dan akurasi yang tinggi, (3) Responsiveness (daya tangkap), yaitu kemampuan untuk membantu dan memberika pelayanan yang cepat (responsif) dan tepat kepada para pelanggan dengan penyampaian informasi yang jelas. Membiarkan pelanggan menunggu tanpa adanya suatu alasan yang jelas menyebabkan persepsi yang negatif dalam kualitas pelayanan, (4) Assurance (jaminan), adalah kepastian yaitu pengetahuan, kesopan santunan dan kemampuan para pegawai perusahaan untuk menumbuhkan rasa percaya para pelanggan kepada pelayanan perusahaan yang memiliki beberapa komponen antara lain: (a) Communication (komunikasi), yaitu secara terus menerus memberikan informasi kepada pelanggan dalam bahasa dan penggunaan kata yang jelas sehingga para pelanggan dapat dengan mudah mengerti di samping ituperusahaan hendaknya dapat secara cepat dan tanggap dalam menyikapi keluhan dan komplain yang dilakukan oleh pelanggan, (b) Credibility (kredibilitas), perlunya jaminan atas suatu kepercayaan yang diberikan kepada pelanggan, believability atau sifat kejujuran. Menanamkan kepercayaan, memberikan kredibilitas yang baik bagi perusahaan pada masa yang akan datang, (c) Security (keamanan), adanya suatu kepercayaan yang tinggi dari pelanggan akan pelayanan yang diterima. Tentunya pelayanan yang diberikan memberikan suatu jaminan kepercayaan yang maksimal. (d) Competence (kompetensi) yaitu keterampilan yang dimiliki dan dibutuhkan agar dalam memberikan pelayanan kepada pelanggan dapat dilaksanakan dengan optimal. (e) Courtesy (sopan santun), dalam pelayanan adanya suatu nilai moral yang dimiliki oleh perusahaan dalam memberikan pelayanan kepada pelanggan. Jaminan aka kesopanan santunan yang ditawarkan kepada pelanggan sesuai dengan kondisi dan situasi yang ada. (f) Empathy (empati), yaitu memberikan perhatian yang tulus dan bersifat individu atau pribadi yang diberikan kepada para pelanggan dengan berupaya memahami keinginan konsumen.

Tingkat kepuasan konsumen dapat ditentukan berdasar pada lima ( 5 ) faktor utama yang harus diperhatikan oleh sebuah perusahaan (Kotler, 2013 : 177), yaitu: (1) Kualitas produk, Konsumen akan merasa puas bila hasil evaluasi menunjukkan bahwa produk yang dibeli itu berkualitas. (2) Kualitas layanan, Kualitas pelayanan yang lebih baik memungkinkan perusahaan untuk meningkatkan kepuasan dan mengurangi ketidakpuasan pelanggan. Semakin baik kualitas pelayanan akan mengurangi kerja ulang dan pada akhirnya angka ketidakpuasan pelanggan dapat ditekan, (3) Emosional, Konsumen akan merasa bangga dan mendapatkan keyakinan orang lain akan kagum terhadap apa yang digunakan, (4) Harga, Produk yang mempunyai kualitas sama tetapi menetapkan harga yang relative murah akan memberikan nilai lebih tinggi kepada konsumen, (5) Biaya, Konsumen yang tidak perlu mengeluarkan biaya tambahan cenderung akan puas terhadap produk / jasa tersebut.

\section{METODE}

Metode yang digunakan dalam penelitian ini adalah dengan menggunakan analisis kuantitatif deskriptif. Untuk pengumpulan data penelitian menggunakan metode survey, observasi dan juga wawancara terhadap responden dengan membagikan kuesioner di lapangan. Penelitian ini melibatkan empat variabel yang terdiri atas satu variabel terikat (dependen) dan tiga variabel bebas (independen). Variabel terikatnya adalah kepuasan konsumen, sedangkan variabel bebas tersebut adalah: (1) ecommerce, (2) kualitas produk dan (3) kualitas layanan. 
Tabel 3. 1

Klasifikasi Variabel dan Indikator

\begin{tabular}{cllll}
\hline No & \multicolumn{1}{c}{ Variabel } & \multicolumn{1}{c}{ Indikator } & Alat Ukur \\
\hline 1 & $\begin{array}{l}\text { Kepuasan konsumen } \\
(\mathrm{Y})\end{array}$ & $\begin{array}{l}\text { Kualitas produk, Kualitas pelayanan, } \\
\text { Emosional Harga Biaya }\end{array}$ & Kuesioner \\
\hline 2 & $\begin{array}{l}\text { E Commerce } \\
\left(\mathrm{X}_{1}\right)\end{array}$ & $\begin{array}{l}\text { Tampilan dan design, Metode pembayaran, } \\
\text { Jaminan keamanan, Pengiriman Kemudahan } \\
\text { dan faslitas }\end{array}$ & Kuesioner \\
\hline 3 & $\begin{array}{l}\text { Kualitas produk } \\
\left(\mathrm{X}_{2}\right)\end{array}$ & $\begin{array}{l}\text { Kehandalan (reliability), Kesesuaian dengan } \\
\text { spesifikasi (conformance to specification), } \\
\text { Daya tahan (durability) Serviceability, Estetika }\end{array}$ & \\
& & $\begin{array}{l}\text { Tangible ( bukti langsung), reliability } \\
\text { (kehandalan), Responsiveness (daya tangkap) }\end{array}$ & Kuesioner \\
4 & $\begin{array}{l}\text { Kualitas Layanance (jaminan), Price/Harga, Empati } \\
\left(\mathrm{X}_{3}\right)\end{array}$ & & \\
& &
\end{tabular}

Sumber: Data yang diolah (2017)

Pengumpulan data dalam penelitian ini meliputi: (1) Kajian Pustaka (data dari internet: Bukalapak, OLX,Tokopedia,Lazada, dan Shoppee). (2) Data Kuesioner responden dilapangan Secara sistematik, bagan alir dalam penelitian ini dapat digambarkan sebagai berikut:

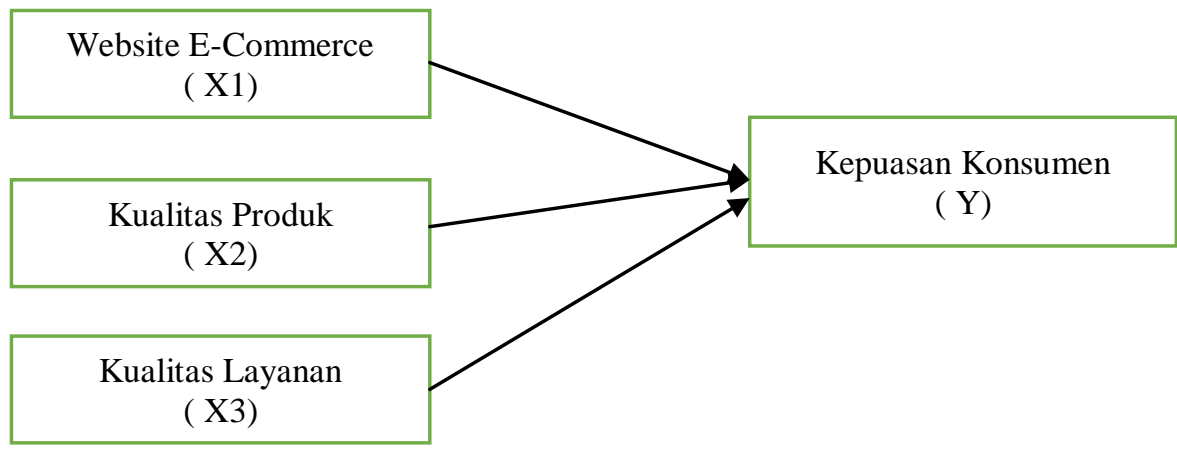

Gambar 3.1

Bagan alir Pemecahan Masalah

Data yang telah diperoleh diolah dan dianalis dengan menggunakan Regresi berganda (MultiRegression), dengan formulasi sebagai berikut: $\mathbf{Y}=\mathbf{a o}+\mathbf{a 1} \mathbf{X}_{1}+\mathbf{a} 2 \mathbf{X}_{2}+\mathbf{a 3} \mathbf{X}_{3}$

Dimana:

$\mathrm{a}_{\mathrm{O}} \quad=$ konstanta

$\mathrm{a} 1, \mathrm{a} 2, \mathrm{a} 3=$ koefisienX1dankoefisien $\mathrm{X} 2$ dan koefisien $\mathrm{X} 3$

$\mathrm{X} 1 \quad=$ E-commerce

$\mathrm{X} 2=$ Kualitas produk

X3 = Kualitas layanan

$\mathrm{Y} \quad=$ KepuasanKonsumen 


\section{HASIL DAN PEMBAHASAN}

Data responden yang diperoleh dikelompokkan berdasarkan jenis kelamin, usia dan pendidikan. Dengan demikian gambaran dari responden berdasarkan pengelompokkan jenis kelamin, usia dan pendidikan, sebagai berikut :

Tabel 4.1

Tabulasi Silang Usia dan Jenis Kelamin

\begin{tabular}{|c|c|c|c|}
\hline \multirow[t]{2}{*}{ USIA } & \multicolumn{2}{|c|}{ JENIS KELAMIN } & \multirow[t]{2}{*}{ TOTAL } \\
\hline & $\mathrm{L}$ & $\mathrm{P}$ & \\
\hline \multirow[t]{2}{*}{ 21-25 TAHUN } & 2 & 3 & $5 \%$ \\
\hline & $2 \%$ & $3 \%$ & \\
\hline \multirow[t]{2}{*}{ 26-30 TAHUN } & 10 & 20 & $30 \%$ \\
\hline & $10 \%$ & $20 \%$ & \\
\hline \multirow[t]{2}{*}{ 31-35 TAHUN } & 9 & 25 & $34 \%$ \\
\hline & $9 \%$ & $25 \%$ & \\
\hline \multirow[t]{2}{*}{ 36- 40 TAHUN } & 10 & 16 & $26 \%$ \\
\hline & $10 \%$ & $16 \%$ & \\
\hline \multirow[t]{2}{*}{ 41- 45 TAHUN } & 2 & 10 & $12 \%$ \\
\hline & $2 \%$ & $10 \%$ & \\
\hline Total & 33 & 74 & 107 \\
\hline
\end{tabular}

Sumber :data primer ( 2017)

Berdasarkan Tabel 4.2 diketahui bahwa responden laki-laki paling banyak $10 \%$ berusia antara 36-40 tahun, sedangkan responden perempuan paling banyak 25\% berusia antara 31-35 tahun.

Tabel 4.1

Tabulasi Silang Pendidikan dan Jenis Kelamin

\begin{tabular}{cccc}
\hline USIA & \multicolumn{2}{c}{ JENIS KELAMIN } & TOTAL \\
\hline & $\mathrm{L}$ & $\mathrm{P}$ & \\
\hline SMA & 5 & 15 & $20 \%$ \\
\hline & $5 \%$ & $15 \%$ & \\
\hline D.3 & 10 & 25 & $37 \%$ \\
\hline S.1 & $10 \%$ & $25 \%$ & \\
\hline S.2 & 12 & 30 & $41 \%$ \\
\hline & $12 \%$ & $30 \%$ & \\
\hline TOTAL & 3 & 7 & $9 \%$ \\
\hline & $3 \%$ & $9 \%$ & 107
\end{tabular}

Sumber : data primer ( 2017)

Berdasarkan Tabel 4.3 dapat diketahui bahwa responden laki-laki maupun responden perempuan paling banyak memiliki tingkat pendidikan S1, yaitu laki-laki $30 \%$ dan perempuan $12 \%$. Hasil tanggapan responden tentang E-Commerce dapat dilihat pada diagram dibawah ini : 


\section{sosio e-kons}

Volume 10, No. 1, 2018, pp. 87-95

e-ISSN: 2502-5449

p-ISSN: 2085-2266

http://journal.lppmunindra.ac.id/index.php/sosio_ekons

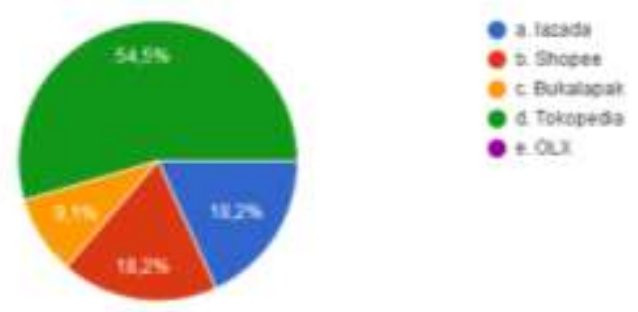

Tanggapan Responden tentang e-commerce

Berdasarkan diagram diatas, nilai rata-rata responden menunjukkan angka sebesar 54,5\% memilih Tokopedia,hal ini menunjukkan bahwa responden setuju jual beli melalui e-commerce karena berada pada prosentase 54,5\%. Hasil tanggapan responden tentang kualitas produk dapat dilihat pada diagram dibawah ini:

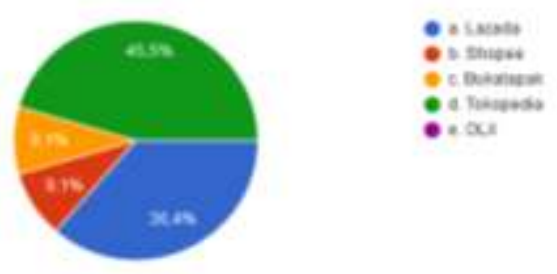

Diagram 4.2

Tanggapan Responden tentang kualitas produk

Berdasarkan diagram diatas,nilai rata-rata responden menunjukkan angka sebesar45,5\% memilih Tokopedia,hal ini menunjukkan bahwa responden setuju jual beli melalui tokopedia kualitas produknya bagus.Hal ini terlihat pada perolehan jumlah berada pada prosentase $45,5 \%$. Hasil tanggapan responden tentang kepuasan konsumen dapat dilihat pada diagram dibawah ini:
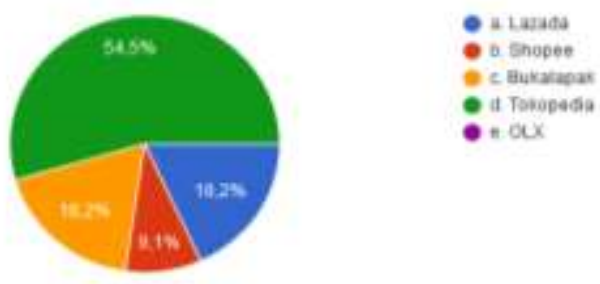

Diagram 4.3

Tanggapan Responden tentang kepuasan

Berdasarkan diagram di atas,nilai rata-rata responden menunjukkan angka sebesar 54,5\% memilih Tokopedia,hal ini menunjukkan bahwa responden setuju jual beli melalui tokopedia lebih merasa senang.hal ini didukung perolehan hasil berada pada prosentase 54,5\%. Hasil tanggapan responden tentang kualitas layanan dapat dilihat pada diagram dibawah ini: 


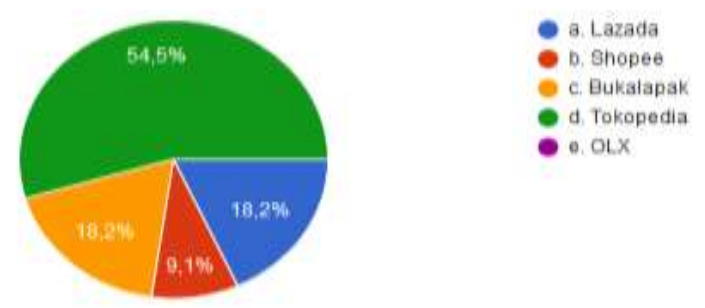

Diagram 4.3

Tanggapan Responden tentang kualitas produk

Berdasarkan diagram diatas,nilairata-rata responden menunjukkan angka sebesar 54,5\% memilih Tokopedia,hal ini menunjukkan bahwa responden setuju jual beli melalui tokopedia lebih merasa senang.hal ini didukung perolehan hasil berada pada prosentase 54,5\%.

\section{Analisis Regresi Linier Berganda.}

Analisis Pengaruh E-commerce, Kualitas Produk dan Kualitas Layanan terhadap Kepuasan Konsumen, hasil analisa regresi berganda ditunjukkan pada table dibawah ini :

Tabel.4.1

Hasil Perhitungan Nilai

Koefisien Persamaan

Regresi

\section{Coefficients $^{\mathrm{a}}$}

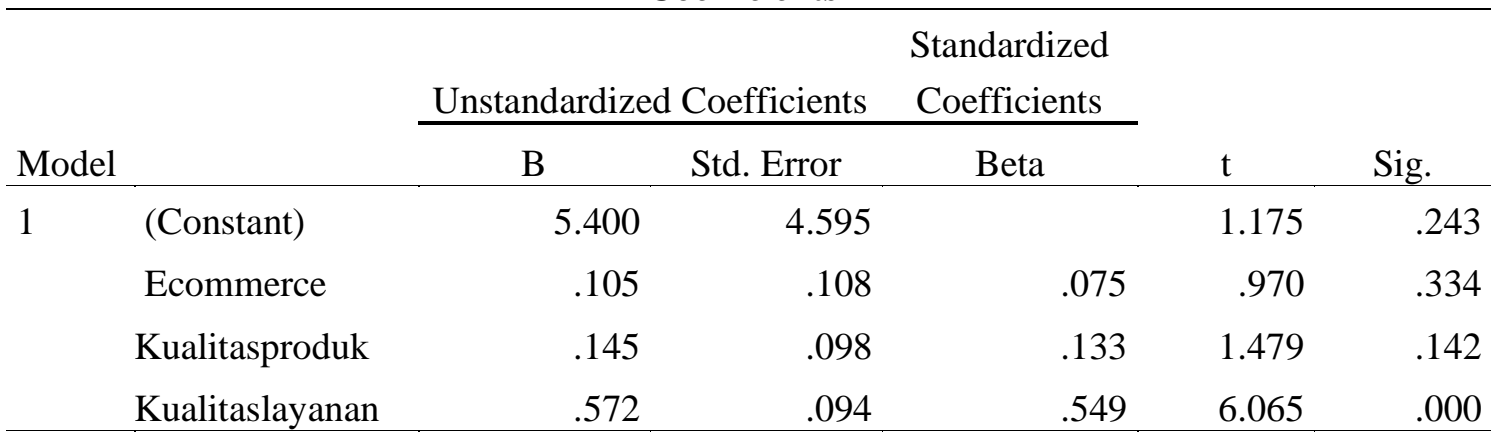

a. Dependent Variable: Kepuasan konsumen

Hasil persamaan regresi linier berganda sebagai berikut:

$Y=5400+0,105 X_{1}+0,145 X_{2}+0,572 X_{3}$

Dari hasil persamaan regresi terlihat bahwa kepuasan konsumen (Y) dipengaruhi oleh website $e$ commerce dan juga kualitas produk. Dan kualitas layanan Dimana pengaruh website $e$ commerce memiliki kontribusi 0.105 sedangkan untuk kualitas produk memiliki konstribusi pengaruh sebesar 0.145 dan kualitas layanan sebesar 0,572.

Dalam penelitian ini sesuai dengan hasil regresi linier dapat dikatakan bahwa pelayanan mempunyai peran penting dalam meningkatkan penjualan produk secara online.Hal ini sejalan dengan penelitian sebelumnya yang membahas mengenai jasa pengiriman dalam transaksi online., namun kualitas produk belum dibahas pada penelitain sebelumnya atau sebaliknya.Oleh karena itu peneliti menggabungkan antara variabel e -commerce,kualitas produk dan variabel kualitas layanan yang tidak kalah penting dalam usaha bisnis online. 


\section{Sosio e-kons}

Volume 10, No. 1, 2018, pp. 87-95

e-ISSN: 2502-5449

p-ISSN: 2085-2266

http://journal.lppmunindra.ac.id/index.php/sosio_ekons

Untuk itu sebaiknya pengusaha e commerce dapat meningkatkan kualitas produk dan pelayanannya untuk mendorong terciptanya penjualan yang signifikan.

\section{SIMPULAN}

1. Adanya website e commerce seperti Tokopedia, Bukalapak, Shopee, Lazada dan OLX memberikan kemudahan bagi konsumen untuk melakukan transaksi penjualan, pembelian dan pembayaran via online.

2. Hasil responden, Tokopedia memiliki ranting lebih tinggi untuk pemilihan transaksi via online hal ini dikarenakan konsumen lebih suka dengan harga dan kualitas produk dan layanan yg baik pada tokopedia.

3. Hasil analisis website e commerce dan perhitungan regresi bahwa kepuasan konsumen sangat dipengaruhi oleh kualitas produk , layanan dan website dengan nilai konstribusi untuk pengaruh website $\left(\mathrm{X}_{1}\right)$ 0.105, kualitas produk $\left(\mathrm{X}_{2}\right)$ 0,145 dan yang paling menentukan adalah pengaruh kualitas layanan $\left(\mathrm{X}_{3}\right)$ sebesar 0,572 .

\section{DAFTAR RUJUKAN}

A.Sufyan.Muhammad, (20 Mei 2017).Diakses tanggal 14 oktober 2017Pertumbuhan eCommerce Indonesia Tertinggi di Dunia Teknologi.http://tekno.liputan6.com /Tekno / Internet.

Alma, Buchari. (2011). Manajemen Pemasaran dan Pemasaran Jasa. Edisi Revisi, Cetakan Kelima. CV. Alfabeta. Bandung.

Kotler, Philip \& Kevin Lane Keller. (2013). Alih Bahasa : Benyamin Molan. Manajemen Pemasaran. Edisi Ketigabelas. Jilid 1. Cetakan Keempat. PT. Indeks. Jakarta.

Ni Made Sinta Wedarini. (2012). Pengaruh kualitas produk terhadap kepuasan dan loyalitas konsumen. Fakultas Ekonomi Universitas Udayana.

Kustian N. (2016). Penentuan dalam Pengiriman Jasa Barang Transaksi E commerce Online.Journal of Applied Business Economics.Vol 2 no. 4 tahun 2016.

Ramanathan. Ramakrishan, Ramanathan, Usha dan Hsiao, Hsia Ling. ( 2012). The Impact of ECommerce on Taiwanese SMEs: Marketing and Operation Effect. UK: Int.J.Production Economics

Sri Wiludjeng SP. (2013). Pengaruh E-Commerce dan Kepercayaan Terhadap Kepuasan Konsumen pada Forum Jual Beli Kaskus di Bandung,SEMANTIK 2013. ISBN: 97926-0266-6.

Suyanto M. (2011), Strategi periklanan E-commerce perusahaan top dunia. Yogyakarta: Penerbit Andi.

Tjiptono, Fandy \& Gregorius Chandra, (2009). Service: Quality Satisfacton. Yogyakarta: Andi. 